\title{
Incomplete childhood vaccination and associated factors among children aged 12-23 months in Gondar city administration, Northwest, Ethiopia 2018
}

\author{
Ayenew Engida Yismaw ${ }^{1 *}$, Nega Tezera Assimamaw² ${ }^{2}$ Netsanent Habetie Bayu ${ }^{3}$ \\ and Shegaye Shumet Mekonen ${ }^{4}$
}

\begin{abstract}
Objective: Despite the fact that immunization services are offered free of charge in Ethiopia but the coverage of complete vaccination is still low. The aim of the study is to determine incomplete vaccination and associated factors among children aged 12-23 months in Gondar city administration, Northwest Ethiopia, 2018.

Result: The proportion of incomplete vaccination among children aged 12-23 months in Gondar city adminstration was $24.3 \%(95 \% \mathrm{Cl} 19.3,29.2)$. Knowledge about the benefits of vaccination ( $\mathrm{AOR}=6.1(95 \% \mathrm{Cl} 1.3,28.9)$, the age at which the child begins vaccination $(A O R=2.4(95 \% \mathrm{Cl} 1.09,8.4)$ time taken to reach nearby health facility and means of transportation to nearby health facility $(A O R=0.2295 \% \mathrm{Cl} 0.06,0.9)$ have statistically significant association with incomplete vaccination. In the current study the proportion of incomplete vaccination was found to be high. Increasing the awareness about vaccination for child care givers and further improve caregiver's knowledge towards the benefit of vaccination is important.
\end{abstract}

Keywords: Incomplete childhood vaccination, Children aged 12-23 months, Gondar city administration, Ethiopia

\section{Introduction}

Immunization is one of the cost-effective public health intervention methods to prevent and eliminate lifethreatening infectious diseases and is estimated to avert between 2 and 3 million deaths each year where vaccinepreventable diseases accounts for the death of over 2 million children in a year and majority of them existed in Sub-Saharan Africa [1, 2].

Comparing to the developed world, children in SubSaharan Africa are more than 15 times to die before age of 5 years due to preventable and treatable diseases using simple, affordable intervention. Also, 5.6 million children under the age of 5 years died in 2016 [3, 4]. The rate of

\footnotetext{
*Correspondence: ayenewe07@gmail.com

1 Department of Clinical Midwifery, School of Midwifery, College of Medicine and Health Sciences, University of Gondar, P.O. BOX: 196, Gondar, Ethiopia

Full list of author information is available at the end of the article
}

full immunization rises with parents' educational level and the frequency of mother's health care utilization [5]. After WHO had launched Expanded Programme on Immunization in 1974, children were prevented from vaccine-preventable diseases that is diphtheria, measles, pertussis, tetanus, polio, tuberculosis ranging from 5 to $83 \%[6,7]$.

The report has shown that 3 out of 4 Ethiopian children had an incomplete vaccination. Owing to this, vaccinepreventable diseases were accountable for the death of 1 in 12 children before celebrating their fifth birthday [8].

About two-thirds (62.8\%) of children were not fully immunized by 1 year of age and $36.4 \%$ were partially and incorrectly immunized because of parents objection, disagreement or concern about safety, long distance walking and long waiting time at health facility which could be avoided easily, especially for rural areas where immunization coverage is below the expected national coverage 
(minimum 80\%) $[9,10]$. Reasons for incomplete vaccination were associated with accessibility to the vaccination sites, no schooling of mothers and children born at home [11].

The routine immunization program in Ethiopia has shown progressive expansion since inception in 1980. In EFY 2005 pentavalent 3 immunization coverage was $87.6 \%$, pneumococcal conjugate vaccine (PCV) 3 immunization coverage $80.4 \%$, measles immunization coverage $83.2 \%$, and the percentage of fully immunized children $77.7 \%$ (FMOH) [12, 13]. Coverage rose from $52 \%$ in 2003 to $86 \%$ in 2010 because of the initiation of the Health Extension Program at the community level and implementation of reaching every district (RED) approach with support from partners contributed significantly to the success registered in immunization program. However, EPI coverage stagnated between 83 and $86 \%$ for 3 successive years after 2010. A national coverage survey conducted in 2012 indicated Penta-valent 3 coverage of $65 \%$. The government with support from WHO and partners developed a national immunization improvement plan covering the period 2014-2015, with the objective of reducing the number of unimmunized children by $10 \%$ every year, reaching $90 \%$ coverage in every region and $80 \%$ in all zones by end of 2015 [14]. The EPI stated in Ethiopia in 1980, with the aim of reducing mortality and morbidity of children and mothers from vaccinepreventable diseases by giving free of charge in the public sectors and NFO operating in the field of health [5]. A community-based cross-sectional study conducted in Northwest Ethiopia on vaccination coverage showed that $24.6 \%$ and $17 \%$ were not vaccinated at all and partially vaccinated respectively [15]. A community based cross sectional study conducted in Lay Armachiho District, North Gondar Zone, Northwest Ethiopia showed that incomplete childhood vaccination was $24 \%$ and the main reasons were fear of side effects, shortage of vaccine in the health facility showing lack of accessibility and absence of vaccinaters [16]. A Community Based Assessment on Immunization Coverage in Gondar City reported that $43 \%$ were partially vaccinated and $14.1 \%$ were not vaccinated at all [17]. The most frequently reported reasons for incomplete or not vaccination were fear of side effects, shortage of vaccines in the health facility inconvenient appointment time, political instability and movability from rural to the city due to this problem. This study was therefore conducted to determine and identify factors associated with incomplete vaccination among children aged 12-23 months in Gondar city and can be used up by researchers, and policymakers as a baseline to design strategies that can mitigate the burden of vaccine-preventable diseases.

\section{Main text}

\section{Methods}

\section{Study design, period and area}

Community based cross-sectional quantitative study was done from April 1 to May 30, 2018, to assess incomplete childhood vaccination and associated factors among children aged 12-23 months in Gondar city, Northwest, Ethiopia 2018.

The study was done in Gondar city which is located $750 \mathrm{~km}$, northwest far from the capital city of Ethiopia Addis Ababa. Gondar is one of the historical places which is the well-known city with its medieval castle and decorated churches found by emperor Fasilldes established since 1632 E.C. According to the recent administration, the city has 12 sub-city administration areas which consisted of 21 kebeles. Gondar is one of the ancient and densely populated city in Ethiopia. The city has 9 health centers and one referral hospital that serving the population of Gondar city and outside.

The source population were all mothers/caretakers with children aged 12-23 months in Gondar city and the study population were mothers/caretakers with children who were available during the data collection period.

Households with at least one live children aged 12-23 months who live for 6 months prior to the study period in the study area were eligible for this study.

Households with at least one live child of aged between 12 and 23 months, and residence of Gondar City Administrations whose mother/caretaker can brought vaccination card or remembered vaccination history were included in the study and those who didn't brought vaccination card or didn't remembered vaccination history of the child were excluded.

\section{Sample size and sampling procedure}

The sample size was calculated by using the single population proportion formula $\mathrm{n}=\left((\mathrm{Z} \alpha / 2)^{2} \mathrm{P}(1-\mathrm{P})\right) / \mathrm{d}^{2}$ with the following assumptions: $23.2 \%$ proportion of incomplete vaccination on a previous study done in Sinana District, Ethiopia [14], A 95\% confidence level, 5\% precision, and $10 \%$ none response rate were used. The sample sizes calculated were 301 . From 12 sub-city administrations four were selected with simple random sampling method and the samples were proportional allocated to each subcity administrations and the sample units were selected with systematic random sampling technique by calculating the interval value of 2 and with lottery method every second child was interviewed.

\section{Operational definition}

Incomplete (partial) immunization If the child missed at least one of the recommended vaccines [7]. 
Knowledge about a schedule of immunization If the mothers know the schedules for all types of vaccines.

\section{Data collection instrument and process}

The data collection tool was developed by reviewing different literatures. The data were collected with face to face interview of mothers or immediate caretakers of the child. Vaccination status was determined by obtaining vaccination cards from the mother/caretaker or by vaccination history from the mother/caretaker or both. Six diploma and two BSc. degree graduated Nurses were recruited for data collection, and supervision, respectively. To ensure data quality, a 2 day training was given to data collectors and supervisors. The questionnaire was pre-tested from unselected city administration to check the appropriateness of the questions.

\section{Data analysis}

The data were checked for completeness, and entered into EPI-info version 7 and transferred to SPSS version 20 for analysis. Descriptive statistics with percentages were employed. All variables were analyzed in bivariate logistic regression and those variables having P-value less than 0.2 were intered to multivariable logistic regression analyses. In multivariable logistic regression analyses variables with P-value less than 0.05 were considered as significant. Hosmer-Lemeshow goodness of fit test was used to check the model fitness. Adjusted odds ratio with $95 \%$ confidence interval was used to determine the presence, and direction of association between covariates and the outcome variable.

\section{Results}

Socio-demographic characteristics

A total of 301 Mothers/caregivers of children aged between 12 and 23 months were interviewed and the response rate was $100 \%$. The immediate caregivers of the children were mothers 109 (36.2\%), both mother and father 191 (63.5\%). Nearly all 283 (94\%) of the caregivers were married (Table 1 ).

\section{Knowledge and access on Immunization and Vaccine preventable diseases}

Majority 284 (94.4\%) of caregivers had heard/seen about vaccination and vaccine preventable diseases as a specific program. The major sources of information was health workers $261(86.7 \%)$. Most of the respondents $260(86.4 \%)$ know measles as a vaccine preventable disease while $286(81.4 \%)$ stated tetanus and followed by polio $233(77.4 \%)$ as vaccine preventable diseases. Nearly four-fifth 241 (80\%) and three-fourth
Table 1 Socio-demographic characteristics of caregivers and children in Gondar city administration, Northwest Ethiopia, $2018(n=301)$

\begin{tabular}{|c|c|c|}
\hline Variable & Frequency & Percent \\
\hline \multicolumn{3}{|l|}{ Child sex } \\
\hline Male & 159 & 52.8 \\
\hline Female & 142 & 47.2 \\
\hline \multicolumn{3}{|l|}{ Mother marital status } \\
\hline Married & 283 & 94.0 \\
\hline Divorced & 14 & 4.7 \\
\hline Single/widowed & 4 & 1.3 \\
\hline \multicolumn{3}{|l|}{ Care taker } \\
\hline Mother & 109 & 36.2 \\
\hline Father & 1 & 0.3 \\
\hline Both & 191 & 63.5 \\
\hline \multicolumn{3}{|c|}{ Mothers/care taker educational status } \\
\hline Unable to read and write & 46 & 15.5 \\
\hline Able to read and write & 36 & 12.0 \\
\hline $1-8$ grade & 67 & 22.3 \\
\hline 9-12 grade & 78 & 25.9 \\
\hline College, university & 74 & 24.6 \\
\hline \multicolumn{3}{|c|}{ Mothers/care taker occupation } \\
\hline Housewife & 181 & 60.1 \\
\hline Government employ & 53 & 17.6 \\
\hline Merchant & 42 & 14.0 \\
\hline Daily laborer & 15 & 5.0 \\
\hline Farmer & 10 & 3.3 \\
\hline \multicolumn{3}{|l|}{ Religion } \\
\hline Orthodox & 258 & 85.7 \\
\hline Muslim & 35 & 11.6 \\
\hline Protestant/catholic & 8 & 2.6 \\
\hline \multicolumn{3}{|l|}{ Ethnicity } \\
\hline Amhara & 287 & 95.3 \\
\hline Kimant & 9 & 3.0 \\
\hline Tigre/oromo & 5 & 1.7 \\
\hline \multicolumn{3}{|l|}{ Number of family size } \\
\hline$\leq 4$ & 215 & 71.4 \\
\hline$\geq 5$ & 86 & 28.6 \\
\hline \multicolumn{3}{|l|}{ Alive children } \\
\hline$\leq 4$ & 143 & 47.5 \\
\hline$\geq 4$ & 158 & 52.4 \\
\hline
\end{tabular}

$220(73 \%)$ of respondents knew that the vaccination program should be started at the age of birth and finished at the age of 9 months. Among respondents 213 (70.8\%) of them knew five sessions are needed to fully completed child vaccination. Almost all 290 (99.0\%) of study participants lived nearby health facility to get vaccination service. About 129 (42.9\%) of care takers use transportation means to the nearby health facility to get vaccination service (Table 2). 
Table 2 Mothers/Caregiver's knowledge and access on immunization and vaccine preventable diseases in Gondar city administration, Northwest Ethiopia, 2018 $(n=301)$

\begin{tabular}{|c|c|c|}
\hline Variable & Frequency & Percent \\
\hline \multicolumn{3}{|l|}{ Heard or seen about vaccination } \\
\hline Yes & 284 & 94.4 \\
\hline No & 17 & 5.6 \\
\hline \multicolumn{3}{|l|}{ Source of information } \\
\hline Community members & 38 & 12.6 \\
\hline Health workers at health facility & 261 & 86.7 \\
\hline Health extension workers & 192 & 63.8 \\
\hline Mass media/magazine & 88 & 29.2 \\
\hline Government & 11 & 3.7 \\
\hline \multicolumn{3}{|l|}{ Benefit of vaccinating a child } \\
\hline Yes & 292 & 97.0 \\
\hline No & 9 & 3 \\
\hline \multicolumn{3}{|c|}{ Mention vaccine preventable diseases } \\
\hline Measles & 260 & 86.4 \\
\hline Mumps & 230 & 76.4 \\
\hline Polio & 233 & 77.4 \\
\hline $\mathrm{TT}$ & 246 & 81.4 \\
\hline Hep.B & 43 & 14.3 \\
\hline Haemophilus influenza & 42 & 14.0 \\
\hline Diarrhea & 181 & 60.1 \\
\hline $\mathrm{TB}$ & 222 & 73.8 \\
\hline Pneumonia & 169 & 56.1 \\
\hline Pertussis & 202 & 67.1 \\
\hline \multicolumn{3}{|c|}{ Vaccination may cause health problem } \\
\hline Yes & 18 & 6.0 \\
\hline No & 283 & 94.0 \\
\hline \multicolumn{3}{|l|}{ Age to begin vaccination } \\
\hline Just after birth & 241 & 80.0 \\
\hline Four weeks after birth & 5 & 1.7 \\
\hline Six weeks after a birth & 55 & 18.3 \\
\hline \multicolumn{3}{|l|}{ Sessions needed for full vaccination } \\
\hline One & 2 & 0.7 \\
\hline Two & 3 & 1 \\
\hline Three & 16 & 5.3 \\
\hline Four & 67 & 22.2 \\
\hline Five & 213 & 70.8 \\
\hline \multicolumn{3}{|l|}{ Age to complete vaccination } \\
\hline 6 months & 70 & 23.2 \\
\hline 9 months & 220 & 73.0 \\
\hline 12 months & 11 & 3.6 \\
\hline \multicolumn{3}{|c|}{ A nearby health facility with vaccination } \\
\hline Yes & 298 & 99.0 \\
\hline No & 3 & 1.0 \\
\hline \multicolumn{3}{|l|}{ Type of health facility } \\
\hline Health centre & 209 & 69.0 \\
\hline Hospital & 92 & 31.0 \\
\hline
\end{tabular}

Table 2 (continued)

\begin{tabular}{lcc}
\hline Variable & Frequency & Percent \\
\hline Transportation to health facility & & \\
By walk & 172 & 57.1 \\
By car & 129 & 42.9 \\
How long does it take to health facility & & \\
Less than 15 min & 136 & 45.2 \\
15-30 min & 142 & 47.2 \\
30 min-1 h & 23 & 7.6 \\
\hline
\end{tabular}

\section{Child vaccination}

In this study, 73 (24.3\%) with 95\% CI $(19.3,29.2)$ of the children were incomplete for recommended vaccination. About 296 (98.7\%) of participants were received routine vaccination where as $5(1.6 \%)$ were received from mass campaign of polio and measles. Majority 259 (86\%) of the respondents reported that the first polio vaccine given in the first 2 weeks. The main reason for defaulting for vaccination 49 (16.3\%) were not knowing vaccination time and $31(10.3 \%)$ lack of awareness.

Respondents had reported the route of each vaccination; BCG is an injection in the arm or shoulder that causes scar (93\%), polio is a drop in mouth (86\%), Pentavalent is an injection given in the left thigh (97.3\%), PCV is an injection given in the right thigh (93.7\%) and Rota given as a drop (97\%) and measle is an injection in the arm at the age of 9 months or older (97\%).

\section{Factors associated with incomplete vaccination}

The bivariate analysis showed that care givers educational status, marital status, occupation, heard/seen about vaccination, benefits of vaccination, age at which the child begins vaccination, availability of health facility providing vaccination service, means of transportation to vaccination site, the distance to reach nearby health facility, and health workers advice about vaccination were significantly associated with the outcome variable at $\mathrm{P}$-value $<0.2$. In the multivariable analysis, benefits of vaccination, age at which child begins vaccination, time taken to reach nearby health facility, and means of transportation were remained significant.

Participants who have lack of knowledge about vaccination were 6 times higher incomplete vaccination than those who have good knowledge $(\mathrm{AOR}=6.1,95 \% \mathrm{CI}$ $(1.3,28.9))$. Participants starting vaccination at $4 / 6$ weeks after birth were 2 times higher incomplete vaccination than starting vaccination at or within 2 weeks after birth $(\mathrm{AOR}=2.4,95 \% \mathrm{CI}(1.09,8.4))$. The time taken 15-30 and 30 min- $1 \mathrm{~h}$ to reach nearby health facility 
decreases incomplete vaccination by $78 \%$ and $60 \%$ than time taken less than 15 min to reach nearby health facility $(\mathrm{AOR}=0.2295 \% \mathrm{CI}(0.06,0.9))$ and $(\mathrm{AOR}=0.495 \%$ CI $(0.35,0.72))$, respectively (Table 3$)$.

\section{Discussion}

This study revealed that, incomplete vaccination among children aged 12-23 months was $24.3 \%$ (95\% CI 19.3, 29.2). This finding is in line with the findings in Lay Armachiho District, North Gondar Zone, Northwest Ethiopia 24.1\% [16], in Sinana district, Ethiopia 23.2\%
[18] and Ambo, Ethiopia 23.7\% [19]. This similarity might be due to the implementation strategies that is Reaching Every District (RED), sustainable out reach services (SOS), and delivery of charge free service.

However, the current finding is lower than the findings in Togo 36.2\% [20], Worabe, Ethiopia 39\% [21], Dominican republic 42.8\% [22], Afghanistan, 31\% [23], Nigeria $62.8 \%$ [9], Angola, 37\% [24]. This variation might be due to internal human displacement might increase the risk of defaulting, sociocultural difference, institutional factors like lack of infrastructure and equipments, shortage of supplies, occurrence of natural disaster and endless

Table 3 Factors associated with incomplete vaccination in Gondar city administration, Northwest Ethiopia 2018 ( $\mathrm{n}=301)$

\begin{tabular}{|c|c|c|c|c|}
\hline \multirow[t]{2}{*}{ Characteristics } & \multicolumn{2}{|c|}{ Vaccination status } & \multirow{2}{*}{$\begin{array}{l}\text { COR } \\
95 \% \mathrm{Cl}\end{array}$} & \multirow{2}{*}{$\begin{array}{l}\text { AOR } \\
95 \% \mathrm{Cl}\end{array}$} \\
\hline & Incomplete & Complete & & \\
\hline \multicolumn{5}{|l|}{ Marital status } \\
\hline Married & $64(22.6 \%)$ & $219(77.4 \%)$ & 1.00 & 1.00 \\
\hline Single/divorce/widowed & $9(50.0 \%)$ & $9(50.0 \%)$ & $3.4(1.3,8.98)$ & $2.2(0.2,24.7)$ \\
\hline \multicolumn{5}{|l|}{ Educational status } \\
\hline Unable to read & $20(43.5 \%)$ & $26(56.5 \%)$ & $7.4(2.8,19.5)$ & $0.7(0.1,9.8)$ \\
\hline Able to read & $18(50.0 \%)$ & $18(50.0 \%)$ & $9.6(3.5,26.5)$ & $8.5(0.8,96.0)$ \\
\hline Grade 1-8 & $20(29.9 \%)$ & $47(70.1 \%)$ & $4.1(1.6,10.4)$ & $3.0(0.3,28.3)$ \\
\hline Grade 9-12 & $8(10.3 \%)$ & $70(89.7 \%)$ & $1.1(0.4,3.2)$ & $1.6(0.2,13.4)$ \\
\hline College and university & $7(9.5 \%)$ & $67(90.5 \%)$ & 1 & 1 \\
\hline \multicolumn{5}{|l|}{ Occupation } \\
\hline Housewives & 49 (26.9\%) & $133(73.1 \%)$ & $0.6(0.18,1.6)$ & $0.73(0.36,1.47)$ \\
\hline Farmer & $6(66.7 \%)$ & $3(33.3 \%)$ & $3.0(0.53,16.9)$ & $1.04(0.62,1.75)$ \\
\hline Government employee & $5(9.4 \%)$ & $48(90.6 \%)$ & $0.16(0.04,0.6)$ & $0.3(0.04,2.3)$ \\
\hline Merchant & $7(16.7 \%)$ & $35(83.3 \%)$ & $0.3(0.08,1.1)$ & $2.0(0.2,18.6)$ \\
\hline Daily laborer & $6(40.9 \%)$ & $9(60.0 \%)$ & 1 & 1 \\
\hline \multicolumn{5}{|c|}{ Do you heard/seen about vaccination } \\
\hline Yes & $64(25.5 \%)$ & $220(77.5 \%)$ & 1 & 1 \\
\hline No & $8(47.1 \%)$ & $9(52.9 \%)$ & $3.9(1.4,10.4)$ & $1.1(0.1,13.0)$ \\
\hline \multicolumn{5}{|l|}{ Benefits of vaccination } \\
\hline Yes & $55(22.6 \%)$ & $188(77.4 \%)$ & 1 & 1 \\
\hline No & $18(31.0 \%)$ & $40(69.0 \%)$ & $1.5(0.8,2.9)$ & $6.1(1.3,28.9)^{*}$ \\
\hline \multicolumn{5}{|c|}{ The age at which the child begins vaccination } \\
\hline After birth & $20(10.1 \%)$ & $178(89.9 \%)$ & 1 & 1 \\
\hline Four/six weeks after birth & $53(48.5 \%)$ & $50(48.5 \%)$ & $6.0(5.4,63.0)$ & $2.4(1.09,8.4)^{*}$ \\
\hline \multicolumn{5}{|c|}{ Time taken to reach the nearby health facility? } \\
\hline Less than $15 \mathrm{~min}$ & $27(19.9 \%)$ & $109(80.1 \%)$ & 1 & 1 \\
\hline $15-30 \mathrm{~min}$ & $34(23.9 \%)$ & $108(76.1 \%)$ & $1.3(0.7,2.3)$ & $0.22(0.06,0.9)^{*}$ \\
\hline $30 \mathrm{~min}-1 \mathrm{~h}$ & $12(54.5 \%)$ & $11(45.5 \%)$ & $4.4(1.9,12.4)$ & $0.4(0.35,0.72)$ \\
\hline \multicolumn{5}{|l|}{ Means of transportation } \\
\hline By walk & $54(31.4 \%)$ & $118(68.6 \%)$ & 1 & 1 \\
\hline By car & $19(14.7 \%)$ & $110(85.3 \%)$ & $0.4(0.2,0.6)$ & $0.1(0.03,0.238)^{*}$ \\
\hline \multicolumn{5}{|c|}{ Health worker advice about vaccination } \\
\hline Yes & $56(22.2 \%)$ & $196(77.8 \%)$ & 1 & 1 \\
\hline No & $17(34.7 \%)$ & $32(65.3 \%)$ & $1.9(0.96,3.6)$ & $1.45(0.1,9.3)$ \\
\hline
\end{tabular}

* Variables having P-value $<0.05$ 
conflict, time inconvenience, poor recording, registration and defaulter tracing.

Having incomplete vaccination among participants with lack of knowledge about benefits of vaccination were 6 times higher than those who had good knowledge $[\mathrm{AOR}=6.1,95 \% \mathrm{CI}(1.3,28.9)]$. This is consistent with the findings in Arbegona district south Ethiopia [18], in Lay Armachiho District, North Gondar Zone, Northwest Ethiopia [16] and in Gondar town [17]. This could be due to information and regular education to the community about vaccination benefits, side effects, and when to return to health facilities plays a role to complete childhood vaccination. And also how to handle the child during vaccine side effect related illnesses to avoid such frustration for next appointment and the effect of this situation on the community as a whole.

Participants starting vaccination at $4 / 6$ weeks after birth were 2 times higher incomplete vaccination than those starting vaccination at or within 2 weeks after birth $[\mathrm{AOR}=2.4,95 \% \mathrm{CI}(1.09,8.4)]$. This finding is supported by study conducted in Rural Nigerian [22]. This is because of that lately starting causes missing of some vaccines which were given within the first 2 weeks after delivery. There are also cultural and religious factors that postpartal women and newborn didn't go out of home for the first 2-3 weeks which leads to messing of oral polio vaccine provided in the first 2 weeks. The time taken 15-30 min and $30 \mathrm{~min}-1 \mathrm{~h}$ to nearby health facility decreases incomplete vaccination by $78 \%$ and $60 \%$ than time taken less than $15 \mathrm{~min}$ to reach nearby health facility with $[\mathrm{AOR}=0.22,95 \% \mathrm{CI}(0.06,0.9)]$ and $[\mathrm{AOR}=0.4$, $95 \%$ CI $(0.35,0.72)$ respectively. This finding is contradicted with findings in Sinana district, Ethiopia [18]. This might be due to mothers might forgot weather the child was given the vaccine immediately at birth and lack of registration by delivery attendants at delivery during weekends and night time. And also health care providers may not properly counsel on the next appointments considering their residency near to the health facility.

Participants using car as means of transportation to reach nearby health facility was reduce incomplete vaccination by $90 \%$ as compared to their counter parts $[A O R=0.1,95 \% \mathrm{CI}(\mathbf{0 . 0 3 2}, \mathbf{0 . 2 3 8})]$. This finding was supported by the findings in Sinana district, Ethiopia [18] in Lay Armachiho District, North Gondar Zone, Northwest Ethiopia [16]. This might be due to that transportation is the main factor to get the service timely and properly because vaccination especially BCG and Measel vaccines are provided with limited time and date to avoid unnecessary wastage. So to get these vaccines clients may wait till ten or twenty child may come to open these vaccines and may lead to come again next time this makes clients tyred if transport is easily accessible.

\section{Conclusion}

In the current study the proportion of incomplete vaccination was high compared to national target. Lack of knowledge when the child begins vaccination, means of transportation to health facilities and lack of knowledge about the benefits of vaccination had statistically significant with incomplete vaccination.

The city administration Health office would work to increase community awareness through health education on the benefits and make vaccines easily accessible to complete the entire schedule of vaccination to reduce morbidity and mortality of children from vaccine preventable diseases.

\section{Limitation}

Children's parent or caregivers recall bias that might prone to over or under reporting of immunization status of their children and the sample size was small that may affect its precision.

\section{Abbreviations}

BCG: Bacillus Calment Gurin; Cl: confidence interval; DHS: demographic health survey; DPT: diphtheria, pertussis and tetanus; EDHS: Ethiopian demographic health survey; ETB: Ethiopian Total Birr; EPI: expanded program of immunization; EPI Info: epidemiological information; HEW: health extension worker; MDG: millennium development goal; OR: odd ratio; OPV: oral polio vaccine.

\section{Authors' contributions}

AEY, NTA and SSM wrote the proposal, analyze data and wrote the paper. NHB participated in data analysis and wrote the manuscript. All authors read and approved the final manuscript.

\section{Author details \\ ${ }^{1}$ Department of Clinical Midwifery, School of Midwifery, College of Medicine and Health Sciences, University of Gondar, P.O. BOX: 196, Gondar, Ethiopia. \\ ${ }^{2}$ Department of Pediatrics and Child Health Nursing, School of Nursing, Col- lege of Medicine and Health Sciences, University of Gondar, Gondar, Ethiopia. ${ }^{3}$ Department of Medical Nursing, School of Nursing, College of Medicine and Health Sciences, University of Gondar, Gondar, Ethiopia. ${ }^{4}$ Department of Psychiatry, College of Medicine and Health Sciences, University of Gondar, Gondar, Ethiopia.}

\section{Acknowledgements}

We would like to acknowledge the School of Nursing, College of Medicine and Health Sciences, University of Gondar for their support. We also acknowledge the Gondar city administration Health Office for their cooperation.

\section{Competing interests}

The authors declare that they have no competing interests.

\section{Availability of data and materials}

Data will be available up on responsible request from corresponding author using "ayenewe07@gmail.com".

\section{Consent for publication}

Not applicable.

\section{Ethics approval and consent to participate}

Ethical approval was obtained from the school of Nursing college of medicine and health science University of Gondar. Permission letter from Gondar city administration was also secured before data collection. After discussing the objective of the study, informed written consent was taken from study participants. Names of participants were not included during data collection. 


\section{Funding}

The authors have also declared that no financial support in the research, authorship and publication of this article was received.

\section{Publisher's Note}

Springer Nature remains neutral with regard to jurisdictional claims in published maps and institutional affiliations.

Received: 17 March 2019 Accepted: 22 April 2019

Published online: 29 April 2019

\section{References}

1. Banteyerga $H$. Ethiopia's health extension program: improving health through community involvement. MEDICC Rev. 2011;13(3):46-9.

2. Bishai DM. Global initiatives in universal childhood immunisation. Lancet. 2008;372(9655):2004-5. https://doi.org/10.1016/S0140-6736(08)61853-X.

3. Chan M. The contribution of immunization: saving millions of lives, and more. Public Health Rep. 2014;129(Suppl 3):7-8.

4. Etana B, Deressa W. Factors associated with complete immunization coverage in children aged 12-23 months in Ambo Woreda, Central Ethiopia. BMC Public Health. 2012;12(July):566. https://doi. org/10.1186/1471-2458-12-566.

5. Federal Democratic Republic of Ethiopia Ministry of Health. Supporting evidence-based decision making: towards the achievement of the health millennium development goal; 2014.

6. Garib Z, Vargas AL, Trumbo P, Anthony K, Diaz-Ortega JL, Bravo-Alcántara P, Leal I, Danovaro-Holliday M, Velandia-Gonzalez M. Missed opportunities for vaccination in the Dominican Republic: results of an operational investigation. Biomed Res Int. 2016;2016(January):1-9. https://doi. org/10.1155/2016/4721836.

7. Hu Y, Li Q, Chen E, Chen Y, Qi X. Determinants of childhood immunization uptake among socio-economically disadvantaged migrants in East China. Int J Environ Res Public Health. 2013;10(July):2845-56. https://doi. org/10.3390/ijerph10072845.

8. ICF International. Demographic and health surveys sampling and household listing manual. Calverton: MEASURE DHS; 2012.

9. Jani JV, De Schacht C, Jani IV, Bjune G. Risk factors for incomplete vaccination and missed opportunity for immunization in rural Mozambique. BMC Public Health. 2008;8(May):161. https://doi.org/10.1186/1471-2458-8-161.

10. Yenit MK, et al. Factors associated with incomplete childhood vaccination among children 12-23 months of age in Machakel Woreda, East Gojjam Zone: a case-control study. J Pregnancy Child Health. 2015. https://doi. org/10.4172/2376-127X.1000180.

11. Landoh DE, Ouro-kavalah F, Yaya I, Kahn AL, Wasswa P, Lacle A, Nassoury DI, Gitta SN, Soura AB. Predictors of incomplete immunization coverage among one to five years old children in Togo. BMC Public Health. 2016;16(September):968. https://doi.org/10.1186/s12889-016-3625-5.
12. Legesse E, Dechasa W. An assessment of child immunization coverage and its determinants in Sinana district, Southeast Ethiopia. BMC Pediatr. 2015. https://doi.org/10.4172/2157-7560.S1.025

13. Levels and Trends in Child Mortality Report 2017 | United Nations Population Division | Department of Economic and Social Affairs.

14. Lim SS, Stein DB, Charrow A, Murray CJL. Tracking progress towards universal childhood immunisation and the impact of global initiatives: a systematic analysis of three-dose diphtheria, tetanus, and pertussis immunisation coverage. Lancet. 2008;372(9655):2031-46. https://doi. org/10.1016/S0140-6736(08)61869-3.

15. Tesfaye TD, Temesgen WA, Kasa AS. Vaccination coverage and associated factors among children aged 12-23 months in Northwest Ethiopia. Hum Vaccines Immunother. 2018. https://doi.org/10.1080/21645 515.2018.1502528.

16. Kassahun MB, Biks GA, Teferra AS. Level of immunization coverage and associated factors among children aged 12-23 months in Lay Armachiho District, North Gondar Zone, Northwest Ethiopia: a community based cross sectional study. BMC Res Notes. 2015;8:239.

17. Gizachew $M$, et al. A community based assessment of the immunization coverage and the associated factors of children aged 12-23 months at Gondar Town, Northwest Ethiopia. EC Microbiol. 2015;2(2):247-60.

18. Mugali RR, Mansoor F, Parwiz S, Ahmad F, Safi N, Higgins-Steele A, Varkey S. Improving immunization in Afghanistan: results from a cross-sectional community-based survey to assess routine immunization coverage. BMC Public Health. 2017;17(April):290. https://doi.org/10.1186/s1288 9-017-4193-z.

19. Oleribe O, Kumar V, Awosika-Olumo A, Taylor-Robinson SD. Individual and socioeconomic factors associated with childhood immunization coverage in Nigeria. Pan African Med J. 2017. https://doi.org/10.11604/ pamj.2017.26.220.11453.

20. Oliveira MF, Martinez EZ, Rocha JS. Factors associated with vaccination coverage in children $<5$ years in Angola. Revista de Saúde Pública. 2014;48(6):906-15. https://doi.org/10.1590/S0034-8910.2014048005284.

21. Popova O, Ibarra de Palacios P. Reaching more children with vaccines in developing countries: key challenges of innovation and delivery. Curr Med Res Opin. 2016;32(1):177-81. https://doi.org/10.1185/03007 995.2015.1108910.

22. Abdulraheem IS, Onajole AT, Jimoh AA, Oladipo AR. Reasons for incomplete vaccination and factors for missed opportunities among rural Nigerian children. J Public Health Epidemiol. 2011;3(4):194-203.

23. Sasaki S, Igarashi K, Fujino Y, Comber AJ, Brunsdon C, Muleya CM, Suzuki $H$. The impact of community-based outreach immunisation services on immunisation coverage with GIS network accessibility analysis in periurban areas, Zambia. J Epidemiol Community Health. 2011;65(12):1171-8. https://doi.org/10.1136/jech.2009.104190.

24. Shuaib F, Kimbrough D, Roofe M, McGwin G Jr, Jolly P. Factors associated with incomplete childhood immunization among residents of St. Mary Parish of Jamaica. West Indian Med J. 2010;59(5):549-54.

Ready to submit your research? Choose BMC and benefit from

- fast, convenient online submission

- thorough peer review by experienced researchers in your field

- rapid publication on acceptance

- support for research data, including large and complex data types

- gold Open Access which fosters wider collaboration and increased citations

- maximum visibility for your research: over $100 \mathrm{M}$ website views per year

At BMC, research is always in progress.

Learn more biomedcentral.com/submissions 